\title{
Endocrine control of sexual behavior in sneaker males of the peacock blenny Salaria pavo: Effects of castration, aromatase inhibition, testosterone and estradiol
}

\author{
David Gonçalves *, João Alpedrinha, Magda Teles, Rui F. Oliveira \\ Unidade de Investigação em Eco-Etologia, Instituto Superior de Psicologia Aplicada, Rua Jardim do Tabaco 34, 1049-041 Lisboa, Portugal
}

Received 17 October 2006; revised 2 February 2007; accepted 6 February 2007

Available online 13 February 2007

\begin{abstract}
The effects of castration and sex steroid manipulations on the expression of sexual behavior were investigated in a small fish, the peacock blenny, Salaria pavo. In this species, large males defend nests and attract females while small "sneaker" males reproduce by imitating the female morphology and courtship behavior in order to approach nests during spawning events and parasitically fertilize eggs. Sneakers switch into nest holders in their second breeding season, thus displaying both male and female-like sexual behavior during their lifetime. We tested the effects of castration and of an aromatase inhibitor (Fadrozole, F), testosterone $(\mathrm{T})$ or $17 \beta$-estradiol $\left(\mathrm{E}_{2}\right)$ implants on the expression of male and female-like behavior in sneakers. Sneakers were either sham-operated, castrated or castrated and implanted with vehicle, F, T+F or $\mathrm{E}_{2}+\mathrm{F}$. Seven days after the treatment, sneakers were placed in a tank with a nesting male, two ripe females and an available nest. Castrated fish had lower levels of circulating $\mathrm{T}$ and increased the time spent displaying female typical nuptial coloration. T implants had the opposite effect, inhibiting the expression of femalelike behavior and coloration. $\mathrm{E}_{2}$ implants had no significant effect on the display of sexual behavior but the frequency of aggressive displays decreased. The results agree with previous findings in sneakers of $S$. pavo that demonstrated an inhibition of female-like behavior by 11ketotestosterone (11-KT). The reported increase in $\mathrm{T}$ and 11-KT production when sneakers change into nest holders may thus contribute to behaviorally defeminize sneakers. Contrarily, both $\mathrm{T}$ and $\mathrm{E}_{2}$ failed to promote male-like behavior, suggesting that behavioral masculization during tactic switching depends on other neuroendocrine mechanisms or that the time length of the experiment was insufficient to induce male-like behavioral changes in sneakers.
\end{abstract}

(C) 2007 Elsevier Inc. All rights reserved.

Keywords: Aromatase; Sex steroids; Reproductive behavior; Salaria pavo; Peacock blenny; Androgens; Estrogens; Implants; Alternative reproductive tactics; Fadrozole

\section{Introduction}

The influence of sex steroids on the control of sexual behavior has been investigated in detail in animal models from diverse taxa (e.g. rats, quails, lizards). From these studies, it has long been known that gonadal androgens administered to males promote male-typical sexual behavior. However, estrogen administration to males may also induce male typical sexual displays (e.g. Ball, 1937; Beach, 1942; Guhl, 1949). This paradoxical observation was the basis for the aromatase hypothesis (Naftolin et al., 1975), which suggests that the

\footnotetext{
* Corresponding author. Fax: +351218860954 .

E-mail address: davidg@ispa.pt (D. Gonçalves).
}

masculinizing effects of gonadal testosterone $(\mathrm{T})$ on reproductive behavior are partially dependent on its local conversion to estradiol $\left(E_{2}\right)$ by the enzyme aromatase in the brain. This hypothesis has been thoroughly corroborated by studies in mammals and birds where male sexual behavior was inhibited by blocking brain aromatase and reestablished by administering estrogens (e.g. Adkins et al., 1980; Vagell and McGinnis, 1997; for reviews see Baum, 2003; Ball and Balthazart, 2004).

Surprisingly, although fish have been extensively used to study endocrine mechanisms of sex determination and differentiation (review in Devlin and Nagahama, 2002), the role of the aromatization process on the regulation of fish sexual behavior has been poorly investigated. One reason for this is that the non-aromatisable androgen 11-ketotestosterone (11- 
$\mathrm{KT}$ ) is thought to be the most potent androgen in fish (Borg, 1994). 11-KT is the most abundant circulating androgen in most male teleosts and was shown to restore male sexual behavior in castrated sticklebacks and white perches (Borg, 1987; Salek et al., 2001), to increase male sexual displays in intact bluegill sunfish (Kindler et al., 1991) and to induce male sexual displays in gynogenetic carps (Kobayashi and Nakanishi, 1999). However, in other species the most abundant circulating androgen during reproductive periods is $\mathrm{T}$ (e.g. Kime and Groves, 1986; Oliveira et al., 2001b) and in the only study conducted so far investigating the effects of blocking aromatase in fish sexual behavior, two of three investigated male sexual displays in guppies were reduced by aromatase inhibition (Hallgren et al., 2006). Thus, for some fish species, $\mathrm{T}$ aromatization into E2 may also mediate the expression of male sexual displays. The largely ignored role of brain aromatization of androgens on fish sexual behavior is also surprising as teleosts present by far the highest levels of brain aromatase activity in vertebrates (Callard et al., 1990) and, in fish, aromatase occurs in brain areas involved in the control of reproductive behavior (Forlano et al., 2001; Menuet et al., 2003, 2005 ) and peaks during the species reproductive seasons (e.g. Gelinas et al., 1998; Gonzalez and Piferrer, 2002, 2003; Forlano and Bass, 2005). On the other hand, exogenous estrogen administration to fish has been shown to decrease male sexual behavior (e.g. Bayley et al., 2003; Bjerselius et al., 2001; Doyle and Lim, 2005; Oshima et al., 2003) and there are no published studies suggesting that estrogens promote male sexual behavior in fish. Thus, the role of high aromatase levels in brain areas typically associated with the control of sexual behavior is unclear and, more generally, the mechanisms of neuroendocrine control of sexual behavior in fish are still poorly understood.

Here, the effects of castration and sex steroid manipulation on male and female-like displays were tested in the peacock blenny Salaria pavo. In this species, males are larger than females and have a pronounced head crest and an anal gland in the first two rays of the anal fin (Fishelson, 1963; Papaconstantinou, 1979; Patzner et al., 1986). Males defend nests in crevices or holes and, in the studied population, a shortage of nest sites promotes a strong male-male competition for nests (Almada et al., 1994, 1995). Females compete for the access to nesting males and take the initiative in courtship. Females court males by quickly beating the pectoral fins and open-and-closing the mouth in synchrony while displaying a typical nuptial coloration, which consists of an alternated pattern of vertical dark and light bars in the head and anterior portion of the body (Almada et al., 1995). Nesting males assume a passive role during courtship but occasionally will also court females from the nest with intense but low-frequency jerking movements of the anterior portion of the body (Patzner et al., 1986). Small "sneaker" males are unable to acquire nests and reproduce by imitating the female's morphology, courtship displays and nuptial coloration in order to approach and deceive nesting males and parasitically fertilize eggs (Gonçalves et al., 1996). When compared with size-matched females, small sneakers are equally courted and attacked by nesting males suggesting that their female-mimicry is efficient (Gonçalves et al., 2005).
Sneaker males develop secondary sexual characters and may reproduce as nesting males in their second breeding season ( $T$. Fagundes, D. Gonçalves and R.F. Oliveira, unpublished data). Thus, at least some males perform female-like displays in their first breeding season and male-like displays in the following reproductive seasons. Sneakers have lower circulating and gonadal levels of both T and 11-KT than nesting males, and $\mathrm{T}$ is the most abundant androgen in the two morphs both in the plasma (D. Gonçalves and R.F. Oliveira, unpublished data) and in the gonads (Oliveira et al., 2001a). In sneakers, 11-KT implants inhibit female-like displays and promote the development of male secondary sexual characters but it does not induce male-like sexual behavior (Oliveira et al., 2001d).

In this experiment, the effects of castration and of administration to castrated sneakers of an aromatase blocker, $\mathrm{T}$ or $\mathrm{E}_{2}$ on male and female-like sexual displays were tested.

\section{Methods}

Animals

During the breeding season (June and July 2005), males, females and sneakers were collected at Culatra Island $\left(36^{\circ} 59^{\prime} \mathrm{N}, 7^{\circ} 51^{\prime} \mathrm{W}\right.$, Algarve, Southern Portugal) during morning low tide and transported to a field station located in the island. In the field, sneakers were classified as such if they lacked or had vestigial male typical secondary sexual characters (head crest, anal gland and male-like coloration) and sperm could be easily extruded from their vas deferens by gently pressing the abdomen (Gonçalves et al., 1996). In relation to nesting males, sneakers have proportionally larger gonads that lack a testicular gland (Gonçalves et al., 1996) and this criterion was also used to exclude potential non-sneakers from the experiment during the surgical procedure. Animals were kept in 201 tanks under natural photoperiod $(14 \mathrm{~L} ; 10 \mathrm{E})$ and temperature $\left(24 \pm 2{ }^{\circ} \mathrm{C}\right)$ and fed with frozen cockles until testing. Nesting males were kept together with females and provided with abundant nest sites so that they were defending eggs before the experiment. Sneakers and females used in the experiment were kept in separate tanks.

\section{Reagents}

The aromatase inhibitor Fadrozole (F) was gently donated by Novartis Pharma AG (Basel, Switzerland). $\mathrm{T}$ and $\mathrm{E}_{2}$ were purchased from Steraloids (Newport, USA) and the tritiated water and androstenedione used in the radiometric procedure purchased from PerkinElmer (Oporto, Portugal). All other reagents were purchased from Sigma-Aldrich (Madrid, Spain).

\section{Castration and implant procedure}

After being transported to the field station, sneakers were anesthetized with a light dosage of MS222 (tricaine methanesulfonate, dilution 1:10,000), measured and weighed. To assess treatment effects on male-like typical characters, the head and body height were measured to provide an indicator of head crest development (head height/body height) and the genital papilla and the anal gland development were classified in an ordinal scale from 0 (not developed) to 9 (fully developed). Sneakers were recovered in a small tank with full aeration and transferred to a provisional container provided with shelters in abundance until the surgical procedure. Silastic implants (internal diameter $=1.47 \mathrm{~mm}$, external diameter $=1.96 \mathrm{~mm}$ ) were then prepared and their length adjusted to the sneaker's weight in order to keep the implant concentration equal for all fish. The implant concentration was based on previous studies in fish (Kobayashi et al., 1991; Oliveira et al., 2001c; Modesto and Canário, 2003; Ros et al., 2004) and was of $100 \mu \mathrm{g}$ per gram of fish for T and for the aromatase blocker Fadrozole (F) and of $1 \mu \mathrm{g}$ per gram of fish for $\mathrm{E}_{2}$. Steroids and $\mathrm{F}$ were thoroughly dissolved in castor oil. A total of 54 sneakers were randomly assigned to one of six treatments: (1) Sham; (2) castrated (Cast); (3) castrated controls (C; castor oil 
implanted); (4) castrated $+\mathrm{F}(\mathrm{F})$; (5) castrated $+\mathrm{T}+\mathrm{F}(\mathrm{T}+\mathrm{F})$; (6) castrated + $\mathrm{E}_{2}+\mathrm{F}\left(\mathrm{E}_{2}+\mathrm{F}\right)($ Table 1). In the $\mathrm{T}+\mathrm{F}$ treatment, Fadrozole was co-administered with $\mathrm{T}$ in order to block its synthesis into $\mathrm{E}_{2}$. To control for possible secondary effects of $\mathrm{F}$ administration, $\mathrm{F}$ was also co-administered with $\mathrm{E}_{2}$. Approximately $8 \mathrm{~h}$ after the measuring procedure fish were again anesthetized for the surgical procedure. A $1 \mathrm{~cm}$ abdominal cut was made in the abdomen and, with the exception of fish from the Sham group where testicles were manipulated with blunted tweezers but left intact, all animals were castrated. Fish from the Sham and Cast groups received no implant. In the remaining animals the implant was inserted in the peritoneal cavity. The wound was sutured with silk line (Ethicon, Lisbon, Portugal). Fish were recovered as previously described and kept in 201 tanks, separated by treatment, until being tested. The standard length of fish from the different treatments did not differ (one-way ANOVA: $F_{5,48}=1.6, P=0.15$ ).

\section{Behavioral test}

Seven days after being implanted, sneakers were tested in a mating tactic choice setup previously described by Oliveira et al. (2001d). This period was considered sufficient for steroid-induced behavioral changes to take place as in a previous experiment with $S$. pavo steroid implants that were shown to induce behavioral changes in sneakers after 7 days (Oliveira et al., 2001d). The test intended to assess which of the two male reproductive tactics, sneaking or adopting a nest, sneakers would choose when presented with ripe females and a nesting male, and to allow the quantification of female and male-like displays in sneakers. The test tank was $70 \times 30 \times 40 \mathrm{~cm}$ and contained an established nestholder male in a nest with eggs and an available empty nest. The sneaker was introduced in the tank together with two ripe females and the following variables were recorded for the sneaker: time spent inside the empty nest, frequency of female-like displays towards the nesting male, frequency of male-like displays towards females, time spent displaying the female-like nuptial coloration and frequency of agonistic attacks performed towards females. The observation lasted $1 \mathrm{~h}$ and behavioral variables were quantified using JWatcher software v0.9 (Blumstein et al., 2000). Observers did not know before hand to which experimental treatment the focal animal belonged. A total of 8 different nesting males were used and females were never used twice.

\section{Tissue collection and hormone analysis}

Immediately after being tested, sneakers were anesthetized as previously described. Blood was collected from their caudal vein, centrifuged and kept at $-20{ }^{\circ} \mathrm{C}$ for hormone analyses by radioimmunoassay (RIA). Due to the small size of these fish, in a few animals it was not possible to collect enough blood $(25 \mu 1)$ for the RIA (see Table 3 for $N$ values). Blood plasma was stored at $-20{ }^{\circ} \mathrm{C}$ until steroid extraction. Free steroid fraction was extracted using previously described methodology (Canário and Scott, 1989; Scott and Canário, 1992). Steroid residues were redissolved in phosphate buffer $0.1 \mathrm{M}, \mathrm{pH} 7.6$, containing gelatine $(1 \mathrm{~g} / \mathrm{l})$ and stored again at $-20{ }^{\circ} \mathrm{C}$ until assayed for $11-\mathrm{KT}$, T and $\mathrm{E}_{2}$. The antibody used for the 11-KT assay was kindly donated by D.E. Kime and the corresponding specificity table was published in Kime and Manning (1982). The $\mathrm{E}_{2}$ antibody (reference: 20-ER06) was purchased from Interchim (Montluçon, France ) and the cross-reactivity measured by the supplier varied between $1 \%$ for estrone and $0 \%$ for androstenedione. The $\mathrm{T}$ antibody (reference: RDI-TRK2T2) was purchased from Research Diagnostics

Table 1

Description of the six experimental groups used in the experiment

\begin{tabular}{lllr}
\hline Treatment & Castration & Implant & $N$ \\
\hline Sham & No & No implant & 7 \\
Cast & Yes & No implant & 10 \\
$\mathrm{C}$ & Yes & Vehicle (castor oil) & 7 \\
$\mathrm{~F}$ & Yes & Fadrozole & 9 \\
$\mathrm{~T}+\mathrm{F}$ & Yes & Testosterone+Fadrozole & 11 \\
$\mathrm{E}_{2}+\mathrm{F}$ & Yes & $17 \beta$-estradiol+Fadrozole & 10 \\
\hline
\end{tabular}

Fish from Cast and $\mathrm{C}$ treatments were pooled together in another group, Cast2, to increase statistical power in the comparisons with the remaining groups.
Inc. (Concord, USA) and the cross-reactivity measured by the supplier varied between $16 \%$ for 5 -alpha-dehydrotestosterone and $<0.01 \%$ for $\mathrm{E}_{2}$. For each hormone, circulating plasma levels from all animals were measured within the same assay. Intra-assay coefficients of variation for the T, 11-KT and $\mathrm{E}_{2}$ assays were $9.5 \%, 12.3 \%$ and $5.5 \%$, respectively.

The morphological variables recorded in the first day were again measured to assess variation in the development of male-like characters between treatments. The brain was extracted, immediately kept in liquid nitrogen and later transferred to a $-80{ }^{\circ} \mathrm{C}$ fridge until the radiometric procedure used to measure brain aromatase activity. The abdominal cavity was carefully inspected to check for the implant presence and for the development of gonadal tissue. No fish lost the implant, and no castrated fish had any visible gonadal tissue.

During the experimental procedure the "ASAB guidelines for the use of animals in research" were applied.

\section{Aromatase activity assay}

A radiometric assay modified from Gonzalez and Piferrer (2002) was used to measure aromatase activity in order to confirm that $\mathrm{F}$ significantly reduced brain aromatase activity. This assay measures aromatase activity from the sterospecific loss of $1 \beta-{ }_{-}^{3} \mathrm{H}$ from the tritiated substrate to water during the aromatization reaction (Lephart and Simpson, 1991). Briefly, brains were homogenized in $400 \mu \mathrm{l}$ of ice-cold phosphate buffer $0.05 \mathrm{M}, \mathrm{pH} 7.4$, containing $0.25 \mathrm{M}$ sucrose and $0.01 \mathrm{M}$ dithiothreitol with a Teflon homogenizer. Homogenates were split in $100 \mu 1$ aliquots and frozen at $-80{ }^{\circ} \mathrm{C}$ until the radiometric procedure. $150 \mathrm{nM}$ $\left[1 \beta-{ }^{3} \mathrm{H}\right]$-androstenedione was first preincubated at $37^{\circ} \mathrm{C}$ for $1 \mathrm{~h}$ with a NADPH generating system, consisting of $1 \mathrm{mM}$ NADP, $10 \mathrm{mM}$ glucose-6-phosphate and $2 \mathrm{IU} / \mathrm{ml}$ glucose-6-phosphate dehydrogenase. A $100 \mu \mathrm{l}$ brain homogenate aliquot was then incubated at $30{ }^{\circ} \mathrm{C}$ for $30 \mathrm{~min}$ with $200 \mu \mathrm{l}$ of the hormone/ NADPH solution and $100 \mu 1$ of phosphate buffer. The reaction was terminated by placing tubes in ice and adding $200 \mu 1$ of trichloroacetic acid. Samples were centrifuged and the supernatant extracted with chloroform. The aqueous phase was washed with dextran (0.05\%)-activated charcoal $(0.5 \%)$ and $400 \mu \mathrm{l}$ of the supernatant was counted in a liquid scintillation counter. The protein pellet was dissolved with $0.2 \mathrm{~N}$ of $\mathrm{NaOH}$ and the protein content determined with the Lowry procedure (Lowry et al., 1951). Aromatase activity was expressed as $\mathrm{pmol} / \mathrm{mg}$ protein/hour.

\section{Statistics}

Differences between groups were compared with two-tailed parametric tests. When necessary, data were log or square root transformed to comply with heteroscedasticity and normality assumptions.

The morphological and behavioral effects of castration and hormonal manipulation were assessed by comparing the Cast2, Sham, $\mathrm{F}, \mathrm{T}+\mathrm{F}$ and $\mathrm{E}_{2}+\mathrm{F}$ groups with one-way ANOVAs. When differences were significant $(P<0.05)$, Dunnett post hoc tests were applied to test for specific differences between the control group, Cast2 and the remaining groups.

\section{Results}

\section{Implant validation}

First, to test if the implant procedure per se had a significant effect on the behavior or morphology of sneakers, animals from the Cast (castrated and not implanted) and C (castrated and implanted with vehicle) treatments were compared with unpaired $t$-tests. Fish from these two groups did not differ in circulating levels of T, 11-KT or $\mathrm{E}_{2}(t<1.5, d f=15, P>0.15)$ and no difference in any of the behavioral $(t<1.2, d f=15$, $P>0.25)$ or morphological $(t<1.4, d f=15, P>0.16)$ variables was found, suggesting that the implant per se did not induce any significant change. Animals from the Cast and $\mathrm{C}$ groups were 
thus pooled together in a second control group, Cast2, in order to increase statistical power.

To validate the use of the aromatase blocker, $\mathrm{F}$, differences in brain aromatase activity between animals that received $(\mathrm{F}, \mathrm{T}+\mathrm{F}$ and $E_{2}+F$ ) and did not receive (Sham, Cast2) $F$ were tested. Brain aromatase activity was approximately 3.5-fold lower in animals that received $\mathrm{F}$ when compared with animals that did not receive $\mathrm{F}$ (unpaired $t$-test, $t=5.1, d f=41, P<0.001$, Table $2)$. No difference in brain aromatase activity was recorded between $\mathrm{F}, \mathrm{T}+\mathrm{F}$ and $\mathrm{E}_{2}+\mathrm{F}$ implanted animals (one-way ANOVA, $\left.F_{2,17}=0.0, P=0.99\right)$ or between Sham and Cast2 animals (unpaired $t$-test, $t=0.8, d f=21, P=0.44$ ) (Table 2).

The steroid implant procedure produced the expected effects (Table 3). Fish from the $E_{2}+F$ treatment had significantly higher levels of circulating $\mathrm{E}_{2}$ (unpaired $t$-test, $t=2.7, d f=20$, $P=0.013)$ but not of $\mathrm{T}(t=1.4, d f=25, P=0.172)$ or $11-\mathrm{KT}$ $(t=0.4, d f=25, P=0.671)$ than Cast2 fish (Table 3). Likewise, $\mathrm{T}+\mathrm{F}$ implanted animals had significantly higher levels of circulating $\mathrm{T}(t=5.0, d f=21, P<0.001)$ but not of $\mathrm{E}_{2}(t=0.9$, $d f=20, P=0.335)$ than animals from the Cast2 treatment. However, fish implanted with $\mathrm{T}+\mathrm{F}$ also had significantly higher levels of $11-\mathrm{KT}$ than Cast2 fish $(t=3.9, d f=21, P<0.001)$. The $\mathrm{T}+\mathrm{F}$ implant resulted in an average $\mathrm{T}$ circulating plasma level of $28 \mathrm{ng} / \mathrm{ml}$, close to the maximum physiological level so far measured for $S$. pavo males collected in the field $(36 \mathrm{ng} / \mathrm{ml}, \mathrm{D}$. Gonçalves and R. F. Oliveira, unpublished data). Three of the eleven $\mathrm{T}+\mathrm{F}$ implanted fish had $\mathrm{T}$ values above $36 \mathrm{ng} / \mathrm{ml}$. The levels of 11-KT resulting from the $\mathrm{T}+\mathrm{F}$ implants (maximum, $9.0 \mathrm{ng} / \mathrm{ml}$ ) were all below the physiological maximum measured for the species $(60.0 \mathrm{ng} / \mathrm{ml}, \mathrm{R}$. F. Oliveira, unpublished data). A comparison between the Sham and Cast 2 treatments revealed that castration reduced the circulating levels of the three hormones, but significantly so only for $\mathrm{T}\left(\mathrm{E}_{2}, t=1.6\right.$, $d f=16, P=0.137 ; \mathrm{T}, t=2.2, d f=16, P=0.041 ; 11-\mathrm{KT}, t=1.9$, $d f=20, P=0.078$, Table 3 ).

\section{Behavioral effects}

Groups differed significantly in the frequency of female-like displays towards the nesting male $\left(F_{4,49}=6\right.$., $P<0.001$; Fig. 1$)$. $\mathrm{T}+\mathrm{F}$ fish performed significantly less displays than Cast2

Table 2

Brain aromatase activity measured in the five experimental groups at the end of the experiment

\begin{tabular}{ll}
\hline Treatment & Brain aromatase activity $(\mathrm{pmol} / \mathrm{mg}$ protein $/ \mathrm{h})$ \\
\hline Groups without Fadrozole & \\
Sham $(N=7)$ & $2.83 \pm 0.45$ \\
Cast2 $(N=16)$ & $2.33 \pm 0.43$ \\
Mean \pm S.E. & $2.53 \pm 0.31$ \\
& \\
Groups with Fadrozole & \\
$\mathrm{F}(N=7)$ & $0.71 \pm 0.20$ \\
$\mathrm{~T}+\mathrm{F}(N=7)$ & $0.78 \pm 0.32$ \\
$\mathrm{E}_{2}+\mathrm{F}(N=6)$ & $0.63 \pm 0.11$ \\
Mean $\pm \mathrm{S} . \mathrm{E}$. & $0.71 \pm 0.13$ \\
\hline
\end{tabular}

The number of animals from each group used in the assay is shown in brackets. Values are mean \pm S.E. of mean.
Table 3

Circulating levels of T, 11-KT and $\mathrm{E}_{2}$ measured in the experimental groups at the end of the experiment

\begin{tabular}{llcl}
\hline Treatment & $\mathrm{E}_{2}(\mathrm{ng} / \mathrm{ml})$ & $\mathrm{T}(\mathrm{ng} / \mathrm{ml})$ & $11-\mathrm{KT}(\mathrm{ng} / \mathrm{ml})$ \\
\hline Sham $(N=6)$ & $0.90 \pm 0.42$ & $3.01 \pm 2.26^{*}$ & $2.66 \pm 0.85$ \\
Cast2 $(N=12)$ & $0.27 \pm 0.20$ & $0.06 \pm 0.01$ & $1.11 \pm 0.37$ \\
$\mathrm{~F}(N=6)$ & $0.55 \pm 0.40$ & $0.09 \pm 0.03$ & $0.64 \pm 0.26$ \\
$\mathrm{~T}+\mathrm{F}(N=10)$ & $0.57 \pm 0.24$ & $28.48 \pm 6.48^{*}$ & $4.20 \pm 0.75^{*}$ \\
$\mathrm{E}_{2}+\mathrm{F}(N=10)$ & $3.09 \pm 1.11^{*}$ & $0.16 \pm 0.07$ & $0.94 \pm 0.22$ \\
\hline
\end{tabular}

The number of animals from each group used in the radioimmunoassay is shown in brackets. Values are mean \pm S.E. of mean. * Indicates significant differences $(P<0.05)$ for the Cast 2 treatment.

animals $(P<0.001)$. The remaining groups did not differ from controls $(P>0.13)$. Differences were also recorded for the time spent displaying the female-like nuptial coloration $\left(F_{4,49}=3.9\right.$, $P<0.01$; Fig. 1$)$. T $+\mathrm{F}(P=0.01)$ and Sham $(P=0.04)$ animals spent significantly less time displaying the female coloration in relation to Cast2 fish (remaining groups, $P>0.99$ ). Finally, the frequency of agonistic attacks performed towards females also differed $\left(F_{4,49}=3.2, P=0.02\right.$; Fig. 1$) . \mathrm{E}_{2}+\mathrm{F}$ treated fish
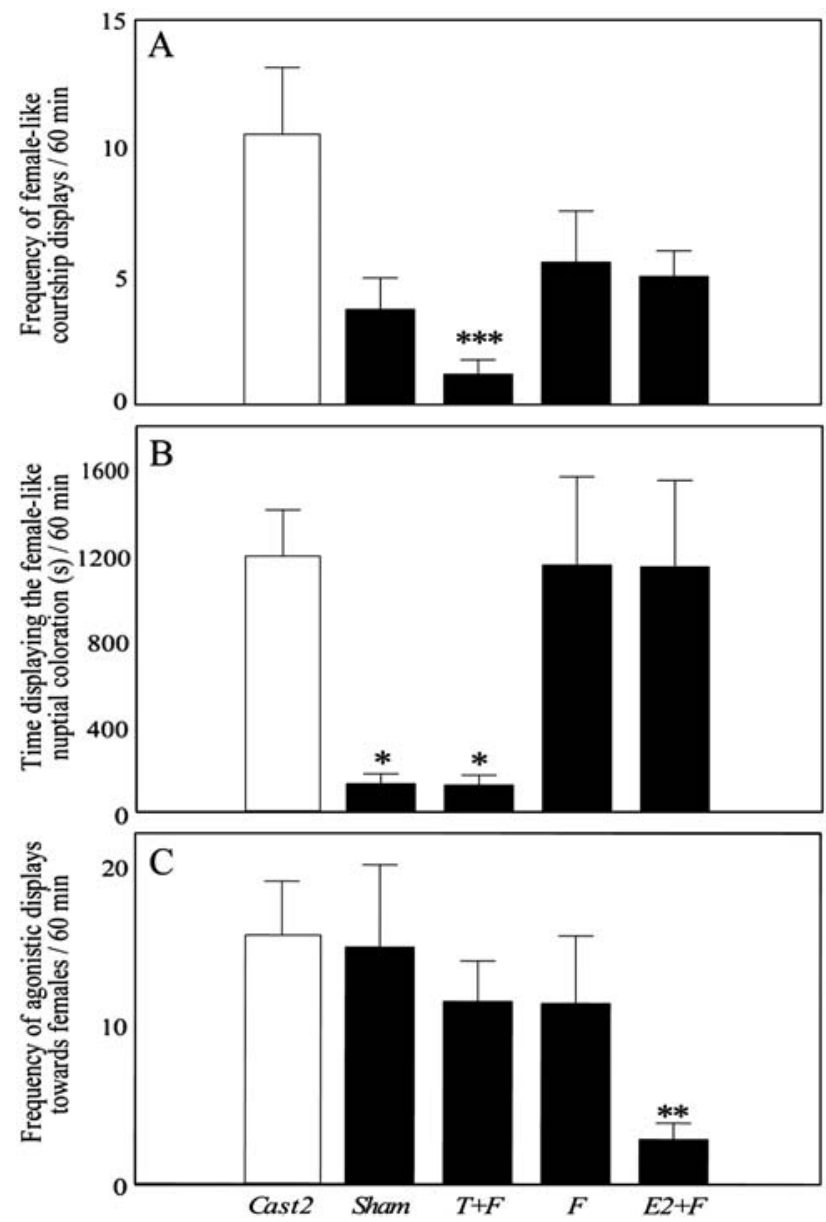

Fig. 1. Behavioral variables recorded for castrated (Cast2) and sham-operated (Sham) fish and for $17 \beta$-estradiol $\left(\mathrm{E}_{2}+\mathrm{F}\right)$, Fadrozole $(\mathrm{F})$, and testosterone $(\mathrm{T}+\mathrm{F})$ implanted fish. (A) frequency of female-like courtship displays directed towards the nesting male; (B) Time spent displaying the female-like nuptial coloration; (C) frequency of agonistic displays directed towards females. Differences to the Cast2 group are marked with $*(P<0.05)$, ** $(P<0.01)$, or $* * *(P<0.001)$. 

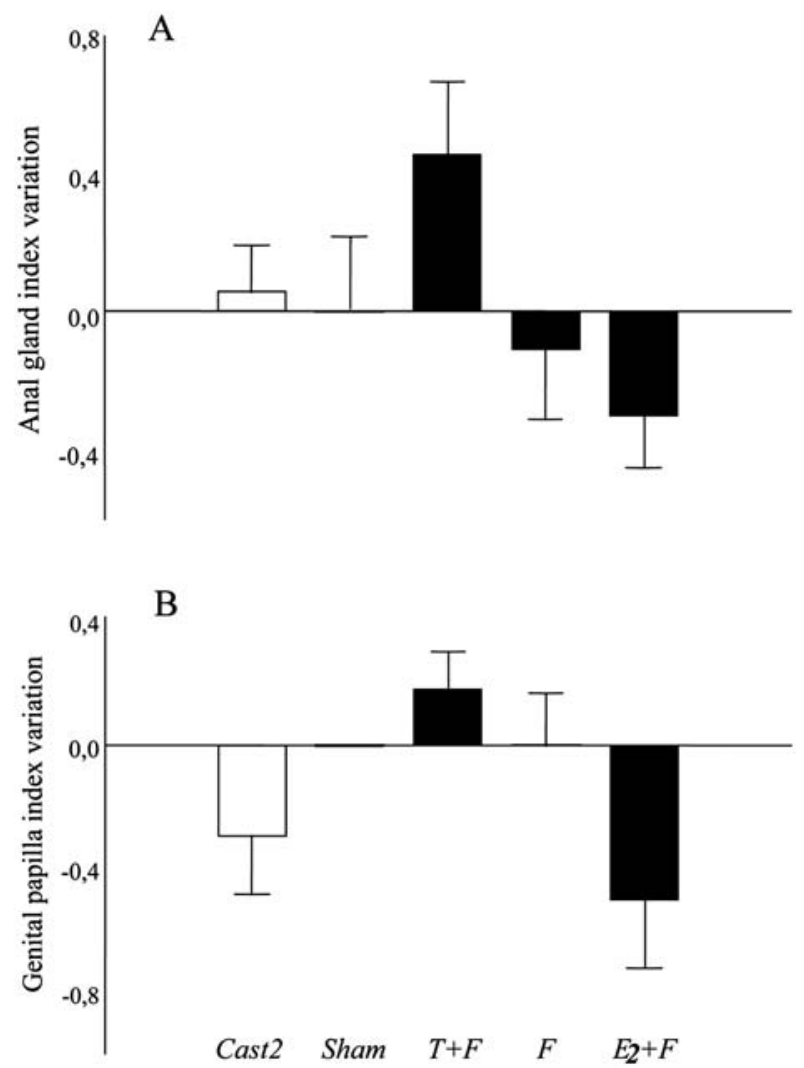

Fig. 2. Variation in (A) anal gland and (B) genital papilla development from the beginning to the end of the experiment in castrated (Cast2) and sham-operated (Sham) fish and in $17 \beta$-estradiol $\left(\mathrm{E}_{2}+\mathrm{F}\right)$, Fadrozole $(\mathrm{F})$ and testosterone $(\mathrm{T}+\mathrm{F})$ implanted fish.

performed less agonistic attacks than Cast2 animals $(P<0.01)$, while no difference was recorded for the remaining groups $(P>0.83)$. No difference between groups was recorded for the time spent inside the available nest $\left(F_{4,49}=0.8, P=0.52\right)$. In all treatments, sneakers never performed nesting male-like courtship displays towards females.

\section{Morphological effects}

The variation in standard length and head crest from the beginning to the end of the experiment was similar between treatments (standard length, $F_{4,49}=0.7, P=0.56$; head crest, $\left.F_{4,49}=0.5, P=0.76\right)$. The variation in the anal gland and genital papilla index was marginally non-significant between groups (anal gland, $F_{4,49}=2.4, P=0.06$; genital papilla, $F_{4,49}=2.2$, $P=0.08$; Fig. 2). $\mathrm{T}+\mathrm{F}$ animals had the most positive developments of these two traits while $\mathrm{E}_{2}+\mathrm{F}$ fish had the most negative variation (Fig. 2).

\section{Discussion}

\section{Female-like behavior}

In relation to sham-operated fish, castrated sneakers had lower circulating levels of $\mathrm{T}$ and spent more time displaying the female-like nuptial coloration. Contrarily, $\mathrm{T}$ treated fish performed less female-like courtship displays and spent less time exhibiting the nuptial coloration. These results strongly suggest that $\mathrm{T}$, or one of its metabolites, inhibits female-like displays in sneakers. Because $\mathrm{T}$ was co-administered with the aromatase blocker, $\mathrm{F}$, inhibition of female-like behavior was probably not a result of local aromatization of $T$ into $E_{2}$. Moreover, $\mathrm{E}_{2}$ implants did not suppress female-like displays. Another T metabolite, 11-KT, may have been responsible for the inhibition of female-like displays in T implanted fish. In this experiment, the metabolic pathway synthesizing 11-KT from $\mathrm{T}$ was not manipulated, and T implanted fish exhibited an increase in 11-KT circulating levels. In a previous study using a similar experimental methodology, 11-KT inhibited female-like displays in sneakers of $S$. pavo (Oliveira et al., 2001d) and in species with alternative reproductive tactics $11-\mathrm{KT}$, but not $\mathrm{T}$, has been suggested to be involved in tactic switching (see Brantley et al., 1993; Oliveira, 2006). Nesting males of S. pavo have naturally higher circulating levels of both $\mathrm{T}$ and 11-KT than sneakers and this difference is higher for 11-KT (D. Gonçalves and R.F. Oliveira, unpublished data). Thus, either both androgens inhibit female-like behavior in S. pavo or 11KT metabolized from T was responsible for the suppression of female-like behavior in this experiment. Androgen inhibition of female-like displays in sneakers of $S$. pavo is contradictory to what has been found in another teleost. In the plainfin midshipman, type I males build nests and court females while type II males cuckold the nests of type I males (Brantley and Bass, 1994). Although type II males have lower levels of circulating 11-KT than type I males (Brantley et al., 1993), 11KT administration to type II males paradoxically promoted cuckoldry (Lee and Bass, 2005). Also in female goldfish, both T and 11-KT failed to suppress female sexual behavior (Kobayashi and Stacey, 1993; Stacey and Kobayashi, 1996). The interpretation of these contradictory results is still unclear, but may relate to the fact that alternative reproductive tactics are sequential in the peacock blenny. When changing into nesting males, sneakers of $S$. pavo will need to both masculinize and defeminize their sexual displays. Contrarily, both in type II males of the plainfin midshipman and in female goldfish the sexual tactic is fixed, and the neural circuits involved in the expression of female-like or female behavior may be more dependent on early hormonal organizational effects and less influenced by hormonal manipulation in adults (see Arnold and Breedlove, 1985; Moore, 1991; Moore et al., 1998).

Castrated sneakers were able to perform female-like behavior, suggesting that these displays are relatively independent of gonadal steroids. This finding is similar to what has been described for goldfish where ovariectomy did not suppress female sexual behavior (Kobayashi and Stacey, 1993). The fact that castration increased female-like behavior and $\mathrm{T}$ implants had the opposite effect suggests that there is a compromise between gonadal androgen production and the expression of female-like behavior in sneakers. Gonadal androgen production, mainly $11-\mathrm{KT}$, is necessary for sperm differentiation and maturation (reviewed in Nagahama, 1994) and our results suggest that an increase in androgen production will suppress female-like displays. Nesting males have a testicular gland that 
sneakers lack, thought to be the main source of gonadal androgens (Oliveira et al., 2001a; Reinboth and Becker, 1986). Even if only testis tissue is considered (i.e. excluding the testicular gland) $\mathrm{T}$ and 11-KT concentrations are, respectively, ten and five-fold higher in nesting males testicular tissue when compared to sneakers (Oliveira et al., 2001a). Thus, development of the testicular gland and an increase in androgen production by testicular tissue during tactic switching will increase androgen production and this in turn will probably be responsible for the suppression of female-like behavior.

\section{Nesting male behavior}

The hormonal manipulations failed to induce typical nesting male behavior in sneakers. Sneakers did not court females or adopt the available nest for significant periods of time in any of the treatments. Thus, neither $\mathrm{T}$ nor $\mathrm{E}_{2}$ promoted nesting malelike behavior in sneakers. In a previous experiment on S. pavo, 11-KT implants also failed to promote nesting male-like behavior in sneakers (Oliveira et al., 2001d). Similar results were found for the rock-pool blenny, where both methyltestosterone (MT) and 11-KT implants failed to promote nesting male sexual displays in satellite males (Oliveira et al., 2001c). Also in type II males of the plainfin midshipman 11-KT did not induce type I male sexual behavior (Lee and Bass, 2005). According to the "relative plasticity hypothesis" proposed under the framework of alternative reproductive tactics, hormonal manipulations in adults should be effective in promoting tactic switching in species with plastic tactics but not in species with fixed tactics (Moore, 1991; Moore et al., 1998). The plainfin midshipman presents fixed tactics and thus fits in this prediction. However, in disagreement with this prediction, in both the rock-pool and the peacock blenny the tactics are sequential and hormonal manipulations failed to induce tactic switching. Moreover, 11KT has been shown to effectively promote male sexual behavior in gynogenetic crussian carps and in female goldfish (Kobayashi and Nakanishi, 1999; Stacey and Kobayashi, 1996). Thus, even in an all-female species and in females of a species with fixed sexual roles, androgens have been shown to effectively promote male sexual behavior. The potential for hormone manipulations to promote male sexual displays in female-like males of $S$. pavo that naturally switch into nesting males should thus be much higher than in the previous examples. Several hypotheses may explain this unexpected result:

1. The time lapse of the experiment was not sufficient for behavioral masculinization. Hormonal manipulations lasted 7 days and this period may not be sufficient for potential hormonal-induced changes involved in nesting male-like displays. In the abovementioned studies for crussian carps and goldfish, hormonal manipulation lasted between 3.5 and 5 months. In the study by Oliveira et al. (2001d), 11-KT effectively promoted the development of nesting male morphological traits in sneakers after 7 days (see below) but not a behavioral switch. Nevertheless, induction of malelike behavior in female gobies could be induced after 1018 days of hormonal treatment with MT (Murphy and
Stacey, 2002) and male behavior in castrated male white perch was restored with 11-KT after 3 weeks (Salek et al., 2001). Also, complete female to male behavioral sex change can be socially induced in a goby species within 5 days (Grober and Sunobe, 1996). Likely, different hormonedependent male traits differ in their temporal response to hormone manipulations and this may vary across species;

2. Nesting male behavior is not facilitated by either $E_{2}$, $T$ or 11$\mathrm{KT}$ in $S$. pavo. This is an unlikely explanation because at least the two androgens are significantly elevated in nesting males when compared to both females and sneakers (D. Gonçalves and R. F. Oliveira, unpublished data; no data available for $E_{2}$ ) and have been demonstrated to promote male-sexual displays in many fish species (for reviews see Borg, 1994; Liley and Stacey, 1983). Nevertheless, in a sexchanging wrasse it was demonstrated that female to male behavioral sex change can be induced in animals that had their gonads removed suggesting that gonadal sex steroids do not play a major role in the induction of male sexual displays in that species (Godwin et al., 1996; for a review see Grober, 1998);

3. Behavioral masculinization depends not only on an increase in circulating sex steroids but also on changes in other components of the steroid pathway. These may include changes in steroid binding globulins, steroid receptors, steroid receptor co-factors or steroidogenic enzymes. Thus, in our experiment, the experimentally induced increase in steroid circulating levels may have been insufficient, per se, to promote male-like behavior. If this is the case, transitional males, i.e. sneakers that are already undergoing the change into nesting males, should be more responsive to the same hormonal treatments.

The only significant effect of $E_{2}$ administration was a decrease in the frequency of aggressive behavior. This has been previously demonstrated in other fish species where exogenous estrogen administration decreased aggressive displays (e.g. Munro and Pitcher, 1985; Bell, 2001). Also, in a sex changing goby, rapid increases in aggression correlate with a decrease in brain aromatase activity, suggesting that a decrease in $E_{2}$ synthesis (or a higher availability of $\mathrm{T}$ ) facilitates aggressive behavior (Black et al., 2005). The fact that $\mathrm{E}_{2}$ implants altered aggressive displays shows that this hormone had a significant physiological effect in our experiment. The lack of an effect of $\mathrm{E}_{2}$ regarding sexual behavior may indicate different temporal dynamics in the response to this hormone by brain circuits mediating sexual displays or that $\mathrm{E}_{2}$ does not significantly affect sexual displays in sneakers. Nevertheless, because sneakers do not naturally display nesting male sexual behavior, the possibility remains that, as suggested for mammals, birds and also guppies (Hallgren et al., 2006), $\mathrm{E}_{2}$ synthesis from $\mathrm{T}$ plays a role in the control of male sexual behavior in $S$. pavo.

\section{Secondary male sexual traits}

Hormone manipulations, namely $\mathrm{T}$ implants, were ineffective in inducing the development of nesting male secondary 
sexual characters. This contrasts with the previous study by Oliveira et al. (2001d) where 11-KT administration to sneakers promoted the development of the genital papilla and anal gland within 1 week. 11-KT has been suggested to be the most effective androgen promoting the differentiation of male secondary sexual characters (see Oliveira, 2006) and thus differences between these two studies may relate to the differential role of $\mathrm{T}$ and $11-\mathrm{KT}$ in male trait differentiation.

\section{Concluding remarks}

Gonadal steroids do not seem to promote female-like sexual displays in sneakers of $S$. pavo as castrated animals were able to display the full suite of female-like behaviors. Moreover, blocking aromatase or administering $\mathrm{T}$ or $\mathrm{E}_{2}$ did not increase female-like displays further suggesting that the activation of these behaviors do not rely on sex steroids. Contrarily, exogenous androgen administration reduced female-like behavior and this is a likely mechanism for behavioral defemination of sexual displays during tactic switching in this species. The endocrine mechanism promoting masculinization of sexual displays during tactic switching in S. pavo is for now unclear as $\mathrm{T}, 11-\mathrm{KT}$ and $\mathrm{E}_{2}$ failed to induce nesting male-like displays in sneakers. Similar experiments in nesting males and future studies with longer-lasting hormonal manipulations in sneakers should contribute to elucidating this issue.

\section{Acknowledgments}

We are grateful to the direction of the Ria Formosa Nature Park for providing essential logistical support. The study was funded by FCT (UI and D 331/2001 and POCTI 38395/BSE/ 2001). D.G. was supported by an FCT post-doc grant (SFRH/ BPD/7188/2001). We thank Cândida Shinn for helping during the experiments. Two anonymous reviewers provided very useful comments on a previous version of the manuscript.

\section{References}

Adkins, E.K., Boop, J.J., Koutnik, D.L., Morris, J.B., Pniewski, E.E., 1980. Further evidence that androgen aromatization is essential for the activation of copulation in male quail. Physiol. Behav. 24, 441-446.

Almada, V.C., Gonçalves, E.J., Santos, A.J., Baptista, C., 1994. Breeding ecology and nest aggregations in a population of Salaria pavo (Pisces, Blenniidae) in an area where nest sites are very scarce. J. Fish Biol. 45, 819-830.

Almada, V.C., Gonçalves, E.J., Oliveira, R.F., Santos, A.J., 1995. Courting females-ecological constraints affect sex-roles in a natural population of the blenniid fish Salaria pavo. Anim. Behav. 49, 1125-1127.

Arnold, A.P., Breedlove, S.M., 1985. Organizational and activational effects of sex steroids on brain and behavior: a reanalysis. Horm. Behav. 19, 469-498.

Ball, J., 1937. Sex activity of castrated male rats increased by estrin administration. J. Comp. Psychol. 24, 135-144.

Ball, G.F., Balthazart, J., 2004. Hormonal regulation of brain circuits mediating male sexual behavior in birds. Physiol. Behav. 83, 329-346.

Baum, M.J., 2003. Activational and organizational effects of estradiol on male behavioral neuroendocrine function. Scand. J. Psychol. 44, 213-220.

Bayley, M., Larsen, P.F., Baekgaard, H., Baatrup, E., 2003. The effects of vinclozolin, an anti-androgenic fungicide, on male guppy secondary sex characters and reproductive success. Biol. Reprod. 69, 1951-1956.
Beach, F.A., 1942. Copulatory behavior in prepuberally castrated male rats and its modification by estrogen administration. Endocrinology 31, 679-683.

Bell, A.M., 2001. Effects of an endocrine disrupter on courtship and aggressive behaviour of male three-spined stickleback, Gasterosteus aculeatus. Anim. Behav. 62, 775-780.

Bjerselius, R., Lundstedt-Enkel, K., Olsen, H., Mayer, I., Dimberg, K., 2001. Male goldfish reproductive behaviour and physiology are severely affected by exogenous exposure to 17beta-estradiol. Aquat. Toxicol. 53, 139-152.

Black, M.P., Balthazart, J., Baillien, M., Grober, M., 2005. Socially induced and rapid increases in aggression are inversely related to brain aromatase activity in a sex-changing fish, Lythrypnus dalli. Proc. R. Soc. B 272, 2435-2440.

Blumstein, D.T., Evans, C.S., Daniel, J.C., 2000. JWatcher 0.9. An introductory user's guide. http://www.jwatcher.ucla.edu.

Borg, B., 1987. Stimulation of reproductive behaviour by aromatizable and nonaromatizable androgens in the male three-spined stickleback, Gasterosteus aculeatus L. Proceedings of the V Congress of European Ichthyologists, pp. 269-271. Stockholm, 1985.

Borg, B., 1994. Androgens in teleost fishes. Comp. Biochem. Physiol. 109C, 219-245.

Brantley, R.K., Bass, A.H., 1994. Alternative male spawning tactics and acoustic signals in the plainfin midshipman fish Porichthys notatus Girard (Teleostei, Batrachoididae). Ethology 96, 213-232.

Brantley, R.K., Wingfield, J.C., Bass, A.H., 1993. Sex steroid levels in Porichthys notatus, a fish with alternative reproductive tactics, and a review of the hormonal bases for male dimorphism among teleost fishes. Horm. Behav. 27, 332-347.

Callard, G.V., Schlinger, B.A., Pasmanik, M., 1990. Nonmammalian vertebrate models in studies of brain-steroid interactions. J. Exp. Biol. Suppl. 4, 6-16.

Canário, A.V.M., Scott, A.P., 1989. Synthesis of $20 \alpha$-hydroxylated steroids by ovaries of the dab (Limanda limanda). Gen. Comp. Endocrinol. 76, $147-158$.

Devlin, R.H., Nagahama, Y., 2002. Sex determination and sex differentiation in fish: an overview of genetic, physiological, and environmental influences. Aquaculture 208, 191-364.

Doyle, C.J., Lim, R.P., 2005. Sexual behavior and impregnation success of adult male mosquitofish following exposure to 17beta-estradiol. Ecotoxicol. Environ. Saf. 61, 392-397.

Fishelson, L., 1963. Observations on littoral fishes of Israel I. Behaviour of Blennius pavo Risso (Teleostei, Blenniidae). Isr. J. Zool. 12, 67-91.

Forlano, P.M., Bass, A.H., 2005. Seasonal plasticity of brain aromatase mRNA expression in glia: divergence across sex and vocal phenotypes. J. Neurobiol. $65,37-49$.

Forlano, P.M., Deitcher, D.L., Myers, D.A., Bass, A.H., 2001. Anatomical distribution and cellular basis for high levels of aromatase activity in the brain of teleost fish: aromatase enzyme and mRNA expression identify glia as source. J. Neurosci. 21, 8943-8955.

Gelinas, D., Pitoc, G.A., Callard, G.V., 1998. Isolation of a goldfish brain cytochrome P450 aromatase cDNA: mRNA expression during the seasonal cycle and after steroid treatment. Mol. Cell. Endocrinol. 138, 81-93.

Godwin, J., Crews, D., Warner, R.R., 1996. Behavioural sex change in the absence of gonads in a coral reef fish. Proc. R. Soc. B 263, 1683-1688.

Gonçalves, E.J., Almada, V.C., Oliveira, R.F., Santos, A.J., 1996. Female mimicry as a mating tactic in males of the blenniid fish Salaria pavo. J. Mar. Biol. Assoc. UK 76, 529-538.

Gonçalves, D., Matos, R., Fagundes, T., Oliveira, R., 2005. Bourgeois males of the peacock blenny, Salaria pavo, discriminate female mimics from females? Ethology 111, 559-572.

Gonzalez, A., Piferrer, F., 2002. Characterization of aromatase activity in the sea bass: effects of temperature and different catalytic properties of brain and ovarian homogenates and microsomes. J. Exp. Zool. 293, 500-510.

Gonzalez, A., Piferrer, F., 2003. Aromatase activity in the European sea bass (Dicentrarchus labrax L.) brain. Distribution and changes in relation to age, sex, and the annual reproductive cycle. Gen. Comp. Endocrinol. 132, 223-230.

Grober, M.S., 1998. Socially controlled sex change: integrating ultimate and proximate levels of analysis. Acta Ethol. 1, 3-17.

Grober, M.S., Sunobe, T., 1996. Serial adult sex change involves rapid and reversible changes in forebrain neurochemistry. NeuroReport 7, 2945-2949. 
Guhl, A.M., 1949. Heterosexual dominance and mating behaviour in chickens. Behaviour 2, 106-120.

Hallgren, S.L., Linderoth, M., Olsen, K.H., 2006. Inhibition of cytochrome p450 brain aromatase reduces two male specific sexual behaviours in the male Endler guppy (Poecilia reticulata). Gen. Comp. Endocrinol. 147, 323-328.

Kime, D.E., Groves, D.J., 1986. Steroidogenesis by gonads of a viviparous teleost, the sailfin molly (Poecilia latipinna), in vitro and in vivo. Gen. Comp. Endocrinol. 63, 125-133.

Kime, D.E., Manning, N.J., 1982. Seasonal patterns of free and conjugated androgens in the brown trout Salmo trutta. Gen. Comp. Endocrinol. 48, $222-231$.

Kindler, P.M., Bahr, J.M., Philipp, D.P., 1991. The effects of exogenous 11-ketotestosterone, testosterone, and cyproterone acetate on prespawning and parental care behaviors of male bluegill. Horm. Behav. 25, 410-423.

Kobayashi, M., Nakanishi, T., 1999. 11-Ketotestosterone induces male-type sexual behavior and gonadotropin secretion in gynogenetic Crucian carp, Carassius auratuslangsdorfii. Gen. Comp. Endocrinol. 115, $178-187$.

Kobayashi, M., Stacey, N., 1993. Prostaglandin-induced female spawning behavior in goldfish (Carassius auratus) appears independent of ovarian influence. Horm. Behav. 27, 38-55.

Kobayashi, M., Aida, K., Stacey, N.E., 1991. Induction of testis development by implantation of 11-ketotestosterone in female goldfish. Zoolog. Sci. 8, 389-393.

Lee, J.S.F., Bass, A.H., 2005. Differential effects of 11-ketotestosterone on dimorphic traits in a teleost with alternative male reproductive morphs. Horm. Behav. 47, 523-531.

Lephart, E.D., Simpson, E.R., 1991. Assay of aromatase activity. Methods in Enzymology. Academic Press, San Diego, pp. 477-483.

Liley, N.R., Stacey, N.E., 1983. Hormones, pheromones, and reproductive behavior in fish. In: Hoar, W.S., Randall, D.J., Donaldson, E.M. (Eds.), Fish Physiology IX Part B. Academic Press, Inc., New York, pp. 1-63.

Lowry, O.K., Rosebrough, N.J., Farr, A.L., Randall, R.J., 1951. Protein determination with the Folin phenol reagent. J. Biol. Chem. 193, 265-275.

Menuet, A., Anglade, I., Le Guevel, R., Pellegrini, E., Pakdel, F., Kah, O., 2003. Distribution of aromatase mRNA and protein in the brain and pituitary of female rainbow trout: comparison with estrogen receptor alpha. J. Comp. Neurol. 462, 180-193.

Menuet, A., Pellegrini, E., Brion, F., Gueguen, M.M., Anglade, I., Pakdel, F., Kah, O., 2005. Expression and estrogen-dependent regulation of the zebrafish brain aromatase gene. J. Comp. Neurol. 485, 304-320.

Modesto, T., Canário, A.V.M., 2003. Hormonal control of swimbladder sonic muscle dimorphism in the Lusitanian toadfish. J. Exp. Biol. 206, 3467-3477.

Moore, M.C., 1991. Application of organization-activation theory to alternative male reproductive strategies: a review. Horm. Behav. 25, 154-179.

Moore, M.C., Hews, D.K., Knapp, R., 1998. Hormonal control and evolution of alternative male phenotypes: generalizations of models for sexual differentiation. Integr. Comp. Biol. 38, 133-151.
Munro, A.D., Pitcher, T.J., 1985. Steroid hormones and agonistic behavior in a cichlid teleost, Aequidens pulcher. Horm. Behav. 19, 353-371.

Murphy, C.A., Stacey, N.E., 2002. Methyl-testosterone induces male-typical ventilatory behavior in response to putative steroidal pheromones in female round gobies (Neogobius melanostomus). Horm. Behav. 42, 109-115.

Naftolin, F., Ryan, K.J., Davies, I.J., Reddy, V.V., Flores, F., Petro, Z., Kuhn, M., White, R.J., Takaoka, Y., Wolin, L., 1975. The formation of estrogens by central neuroendocrine tissues. Recent Prog. Horm. Res. 31, 295-319.

Nagahama, Y., 1994. Endocrine regulation of gametogenesis in fish. Int. J. Dev. Biol. 38, 217-229.

Oliveira, R.F., 2006. Neuroendocrine mechanisms of alternative reproductive tactics in fish. Behav. Physiol. Fish 24, 297-357.

Oliveira, R.F., Canário, A.V., Grober, M.S., 2001a. Male sexual polymorphism, alternative reproductive tactics, and androgens in combtooth blennies (Pisces: Blenniidae). Horm. Behav. 40, 266-275.

Oliveira, R.F., Canário, A.V., Grober, M.S., Santos, R.S., 2001b. Endocrine correlates of male polymorphism and alternative reproductive tactics in the Azorean rock-pool blenny, Parablennius sanguinolentus parvicornis. Gen. Comp. Endocrinol. 121, 278-288.

Oliveira, R.F., Carneiro, L.A., Canário, A.V., Grober, M.S., 2001c. Effects of androgens on social behavior and morphology of alternative reproductive males of the Azorean rock-pool blenny. Horm. Behav. 39, 157-166.

Oliveira, R.F., Carneiro, L.A., Gonçalves, D.M., Canário, A.V., Grober, M.S., 2001d. 11-Ketotestosterone inhibits the alternative mating tactic in sneaker males of the peacock blenny, Salaria pavo. Brain Behav. Evol. 58, 28-37.

Oshima, Y., Kanga, I.J., Kobayashi, M., Nakayamaa, K., Imadaa, N., Honjo, T., 2003. Suppression of sexual behavior in male Japanese medaka (Oryzias latipes) exposed to $17 \beta$-estradiol. Chemosphere 50, 429-436.

Papaconstantinou, C.A., 1979. Secondary sex characters of blennioid fishes (Pisces: Blenniidae). Thalassographica 3, 57-75.

Patzner, R.A., Seiwald, M., Adlgasser, M., Kaurin, G., 1986. The reproduction of Blennius pavo (Teleostei, Blenniidae): V. Reproductive behavior in natural environment. Zool. Anz. 216, 338-350.

Reinboth, R., Becker, B., 1986. In vitro-metabolization of $\left[{ }^{14} \mathrm{C}\right]$ testosterone by spermatogenic tissue and the accessory gland of Blennius pavo (Blenniiformes, Teleostei). Gen. Comp. Endocrinol. 5, 11-16.

Ros, A.F., Bruintjes, R., Santos, R.S., Canario, A.V., Oliveira, R.F., 2004. The role of androgens in the trade-off between territorial and parental behavior in the Azorean rock-pool blenny, Parablennius parvicornis. Horm. Behav. 46, 491-497.

Salek, S.J., Sullivan, C.V., Godwin, J., 2001. Courtship behavior of male white perch, Morone americana: evidence for control by androgens. Comp. Biochem. Physiol., A Physiol. 130, 731-740.

Scott, A.P., Canário, A.V.M., 1992. 17a,20ß-Dihydroxy-4-pregnen-3-one 20sulphate: a major new metabolite of the teleost oocyte maturation-inducing steroid. Gen. Comp. Endocrinol. 85, 91-100.

Stacey, N., Kobayashi, M., 1996. Androgen induction of male sexual behaviors in female goldfish. Horm. Behav. 30, 434-445.

Vagell, M.E., McGinnis, M.Y., 1997. The role of aromatization in the restoration of male rat reproductive behavior. J. Neuroendocrinol. 9, 415-421. 